Original

\title{
Nuevos patrones epidemiológicos y factores de riesgo en cáncer renal
}

Francisco J. Anglada Curado, Pablo Campos Hernández, Rafael Prieto Castro, José L. Carazo Carazo, Juan C. Regueiro López, Francisco Vela Jiménez, Mª José Requena Tapia

Servicio de Urología. Hospital Regional Universitario Reina Sofía. Córdoba, España

\section{Resumen}

El carcinoma renal constituye una de las neoplasias sólidas más letales. En la sociedad occidental se ha producido un constante aumento de la incidencia de este tumor, además de un incremento en la detección de tumores en estadíos precoces. Como ocurre en la mayoría de los cánceres, las causas de la enfermedad permanecen en gran medida desconocidas. Sin embargo, el conocimiento sobre la patogenia última de este tumor avanza rápidamente, permitiendo nuevos tratamientos para la enfermedad avanzada. El conocimiento de la influencia de factores de riesgo fácilmente evitables puede permitir evitar miles de muertes causadas por el cáncer renal.

Palabras clave: Cancer renal. Epidemiología. Factores de riesgo.

\section{New epidemiologic patterns and risk factors in renal cancer} Abstract

Incidence of renal carcinoma, one of the most fatal solid neoplasms, has steadily increased in Western society. Moreover, these tumors are being increasingly detected in their early stages. As with most cancers, the underlying causes of the disease remain unknown. However, understanding of pathogenesis of this tumor is rapidly advancing, and will allow for new treatments for advanced disease. Understanding of the influence of easily avoidable risk factors may allow for prevention of thousands of deaths caused by renal cancer.

Keywords: Renal cancer. Epidemiology. Risk factors

\section{EPIDEMIOLOGÍA DEL CARCINOMA RENAL}

El carcinoma renal constituye el 2,6\% de todas las neoplasias malignas primarias del adulto, es la séptima neoplasia más frecuente en el varón y ocupa el decimosegundo lugar en la mujer. Es la causa del 3\% de las causas de muerte por cáncer. En Estados Unidos se diagnostican más de 30.000 casos nuevos de carcinoma renal cada año, en 2007 se produjeron 12.890 muertes debidas a esta enfermedad. En la UE se diagnosticaron 63.300 casos en 2006 y se produjeron 26.400 muertes $^{1}$.

El carcinoma de células renales constituye el 85\% de las neoplasias malignas primarias del riñón ${ }^{2}$. Presenta una tasa de incidencia que varía entre 4,411,1 casos por cada 100.000 personas y año. La mayor incidencia se produce a partir de los 40 años, con pico entre los 50 y los 70 años. La incidencia es tres veces superior en varones respecto a la de mujeres, así como en la raza negra. Varones y raza negra presentan también una menor supervivencia ${ }^{3,4}$.
Constituye el $2 \%$ de los tumores renales en la edad pediátrica, con una edad de presentación de 8-9 años e histología predominantemente papilar.

La incidencia del cáncer de riñón ha aumentado progresivamente en las últimas tres décadas, en España y en el resto del mundo occidental, a razón de un $3 \%$ anual $^{5}$. En el periodo entre 1930 y 1980 la incidencia aumentó desde el 0,7 al 4,2 por 100.000 en mujeres y del 1,6 al 9.6 en varones. Este aumento de incidencia en este periodo pudo estar motivado, en gran parte, por una mejor disponibilidad para el diagnóstico ${ }^{6}$.

El aumento de la incidencia observado en fechas más recientes, puede también ser en parte debido a un aumento de la detección de tumores incidentales, por la profusión de pruebas diagnósticas radiológicas abdominales. Sin embargo, añadido a la mayor detección de tumores en estadíos precoces, también se observa un incremento en el diagnóstico de carcinomas renales en estadíos avanzados, esta 
mayor incidencia afecta a ambos sexos, y la detección incidental de tumores por estudios radiológicos abdominales no explica por completo el incremento mencionado en la incidencia ${ }^{5,7}$.

Aunque la detección incidental del carcinoma renal supone un mayor número de tumores detectados en estadíos iniciales, localizados, de la enfermedad, a la mayor incidencia de la enfermedad se ha asociado también una constante resistencia al aumento de la supervivencia por unidad de población asociada al tumor, debido a un incremento en el número de tumores avanzados, aunque con un descenso en la proporción global. Actualmente, una cuarta parte de los pacientes diagnosticados de nuevo, lo hacen con la enfermedad avanzada, ello es debido a la aparición tardía de síntomas y a la poca especificidad de los mismos en muchas ocasiones; no existen, además, marcadores que ayuden en la detección precoz de este tumor, y su diagnóstico se basa exclusivamente en pruebas radiológicas. Aproximadamente la mitad de los nuevos diagnósticos se realizan de forma incidental. Un tercio de los pacientes en los que se trata la enfermedad en estadío localizado, sufrirán recidiva de la misma y el 40\% de los pacientes diagnosticados de carcinoma renal morirán de la enfermedad.

En los últimos años se está observando una migración en el estadío del carcinoma renal al diagnóstico, debido a la detección de un mayor número de tumores en estadíos iniciales. Una revisión inicial de los casos de la base de datos americana Surveillance Epidemiology and End Results entre 1973 y 1998 no mostró datos que sugirieran una migración en el estadío al diagnóstico en el carcinoma renal ${ }^{8}$. Sin embargo, más recientemente, se ha publicado una revisión de una serie de 205.963 pacientes, diagnosticados de carcinoma de células renales en Estados Unidos, entre 1993 y $2004^{9}$. Estos autores describen una clara migración del estadío en momento del diagnóstico. Los tumores en estadío I constituyen el 57\% del total al final de la serie, que supone un incremento desde el 43\% al principio de la serie. Cuando incluyen sólo pacientes estadiados tras cirugía, el porcentaje se incrementa hasta el 60\%. El tamaño de las masas diagnosticadas en estadío I se ha reducido también en ese periodo desde $4,1 \mathrm{~cm}$ hasta 3,6. A pesar del aumento de los tumores en estadío I, con la consiguiente disminución de los diagnosticados en estadíos más avanzados, el aumento en la supervivencia global ha sido discreto, probablemente atribuible por entero a la migración hacia estadíos más precoces al diagnóstico. La migración en el estadío se produce en ambos sexos, pero más en mujeres, que son diagnosticadas de tumores en estadío I con mayor frecuencia ${ }^{10}$.

En Europa, la mortalidad por carcinoma renal ha aumentado claramente hasta la década de los noventa del siglo pasado. En la Unión Europea, la mortalidad por cáncer renal alcanzó su máximo a principios de los 90, con una incidencia de 4,8 casos por 100.000 en varones y 2,1 en mujeres. A partir de los primeros años de esa década, la mortalidad comienza a disminuir en países como Francia, Italia y Holanda. Se observa un mayor descenso en varones de mediana edad y en países de Europa occidental. Las tasas de mortalidad se mantienen elevadas en los países de Europa del Este. En Europa del Sur la tendencia es a la estabilización hasta el inicio de siglo y un descenso posterior hasta el año 2004. En general, se recoge también un leve descenso en la incidencia en Europa, si bien éste es desigual. Se ha observado un descenso en la incidencia de carcinoma renal en los países del norte de Europa, excluyendo Gran Bretaña, y un aumento en los países del este de Europa ${ }^{11}$. Las diferencias en incidencia son marcadas, Suecia presentó una incidencia de carcinoma renal en varones en el periodo de 2000-2004 de 10,58 por 100.000 hombres, frente a la de la República Checa de 21,66 por 100.000. Las mayores tasas de mortalidad provienen igualmente de los países del este, con la República Checa a la cabeza, que alcanza el 14,1 para el periodo 2000-2004. La mortalidad en España por carcinoma renal en varones, para el mismo periodo, se sitúa en 3,8 casos por 100.000 hombres, inferior a la registrada en países nórdicos, pero aún el leve ascenso con respecto a periodos anteriores ${ }^{11}$.

\section{Situación del cáncer renal en España}

Durante las últimas décadas del siglo XX, la incidencia de carcinoma renal se incrementó un 2,9\% por año en hombres y un 1,4\% en mujeres, alcanzando una incidencia en varones de 4,8-11,3 casos por 100.000 y en mujeres de 2,3-4,1 $1^{12}$. En España fallecieron por cáncer renal 1.208 varones y 600 mujeres en 2004, lo que corresponde al 1,7\% de todos los fallecimientos por cáncer ${ }^{13}$.

En España se observa una distribución claramente diferenciada de la incidencia de cáncer 
renal $^{14}$, con una mayor incidencia en la zona del País Vasco y Cantabria y una menor incidencia en el sur del país. De forma aislada se observa también una mayor incidencia en Extremadura y el área de Salamanca ${ }^{14}$. En la zona del cantábrico la distribución por sexos es similar. Sin embargo en Extremadura y Salamanca predomina la incidencia sobre mujeres (Fig. 1).

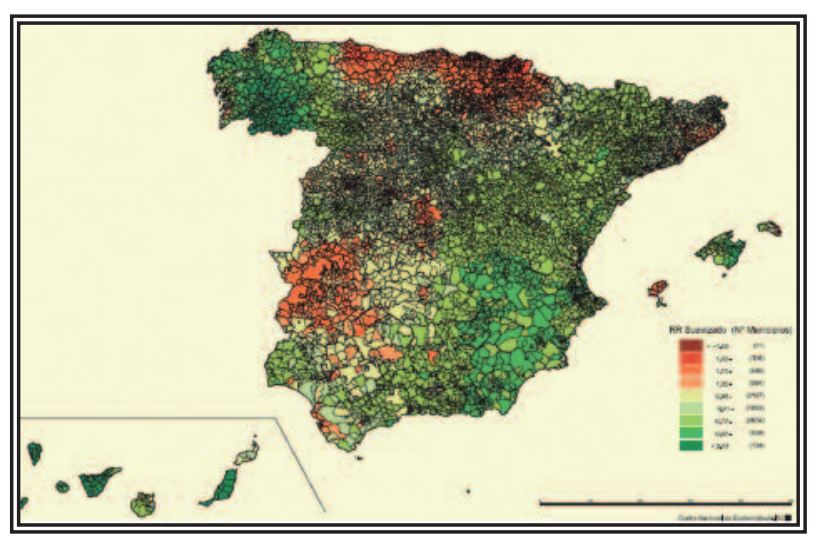

FIGURA 1. Mapa de incidencia de cáncer renal en España. Atlas municipal de Mortalidad por Cáncer en España 1989-1998. Instituto de Salud Carlos III. 2007.

Una de las áreas de mayor incidencia de cáncer de riñón, la cornisa cantábrica y el Golfo de Vizcaya, corresponde a una zona con elevados índices de contaminación ${ }^{15}$, aunque no queda claro que ésta sea la causa principal de la enfermedad.

La explicación a la mayor incidencia de la enfermedad en Extremadura y Salamanca, más frecuente en mujeres, no está tampoco suficientemente esclarecida. Factores ambientales como la presencia de mineral de uranio en el terreno, que puede contaminar el agua potable, pueden explicar en parte el problema. Por otro lado, regiones con niveles de radiactividad natural similares no muestran incidencia elevada de cáncer de riñón.

\section{FACTORES DE RIESGO EN EL CARCINOMA RENAL}

Varios factores de riesgo tienen demostrada su influencia en el desarrollo del carcinoma renal, como el tabaquismo, la insuficiencia renal, la obesidad y la hipertensión ${ }^{16}$, aunque los mecanismos de esta relación no son bien conocidos. La mayor incidencia de la enfermedad en las áreas urbanas con respecto a las rurales, probablemente refleje la influencia del tabaquismo y la obesidad, aparte de una mayor disponibilidad de medios diagnósti$\cos ^{17}$. Las evidencias sobre la relación con los factores de riesgo mencionado provienen de estudios de cohortes, más sólidos que las provenientes de los estudios retrospectivos casos-control. Estos estudios demostraron las primeras asociaciones estadísticas entre factores de riesgo y cáncer, pero estaban sesgados por el tratamiento de la propia enfermedad y la recogida retrospectiva de los datos clínicos $^{18}$.

\section{Tabaco}

El tabaquismo se considera el factor de riesgo más claramente relacionado con el cáncer de riñón.

El riesgo relativo de padecer cáncer de riñón es de 1,38 en los que han fumado alguna vez, en general, con respecto a los que nunca lo han hecho. Este riesgo se incrementa en un 54\% entre los varones y en un $22 \%$ entre las mujeres RR de 1,54 y 1,22 respectivamente $^{19}$.

Aunque existe una vinculación entre el tabaquismo y el riesgo de padecer cáncer renal, con una incidencia 1,7 veces mayor que en la población general para los enfermos fumadores, no se conoce el mecanismo patogénico de la relación. Se ha propuesto, como mecanismo añadido a la exposición de los compuestos carcinogénicos del tabaco, el efecto de la hipoxia crónica causada por el monóxido de carbono y la disminución de la función pulmonar ${ }^{20}$. Existe evidencia de que un compuesto principal del humo del tabaco, el BPDE (benzo-alfa-pyrene diol epoxido) produce mutaciones en el cromosoma 3p21.3, relacionadas con la tumorigénesis de varias neoplasias, entre ellas el carcinoma renal. El grado de susceptibilidad a la mutación inducida por el BPDE en el cromosoma $3 p$, se ha propuesto como marcador de predisposición individual al desarrollo de la enfermedad ${ }^{21}$.

La relación es dosis-dependiente acumulativa, y el riesgo parece disminuir tras el cese del hábito, pero sólo a partir de al menos 10 años tras la interrupción. El riesgo es proporcional al número de cigarrillos diarios consumidos. $\mathrm{El}$ riesgo relativo se incrementa desde 1,6 en los fumadores de 1-9 cigarros al día, a 2,03 en los varones que fuman más de un paquete. En mujeres fumadoras de más de un paquete al día el riesgo se incrementa un $58 \%{ }^{19}$. Se ha demostrado también un mayor riesgo de desarrollar el tumor entre los fumadores ocasionales y los fumadores pasivos ${ }^{22-24}$. 


\section{Insuficiencia renal crónica y diálisis}

El 45\% de los pacientes en diálisis por insuficiencia renal crónica terminal desarrollan enfermedad renal quística adquirida, independientemente del tipo de diálisis al que hayan sido sometidos, de la edad o del origen de la enfermedad renal ${ }^{25}$. Esta enfermedad se caracteriza por la formación bilateral de 3 o más quistes en riñones de pacientes en diálisis. La incidencia de la afección aumenta con la duración de la diálisis, más rápidamente en varones que en mujeres. Alcanza casi el 80\% en pacientes en tratamiento durante más de tres años ${ }^{26}$. Los quistes están tapizados por un epitelio que puede ser hiperplásico con varias capas y proyecciones papilares. Un 8\% de los riñones con enfermedad quística adquirida de la diálisis muestran adenomas, en 1\% de las muestras de autopsias asocian un adenocarcinoma.

El 4-9\% de los pacientes con estos cambios asocian un carcinoma renal, una incidencia 2.500 veces superior a la de la población general. El riesgo aumenta con el tiempo transcurrido desde la primera diálisis. El hecho de padecer enfermedad quística adquirida de la diálisis es un factor de riesgo por sí solo para desarrollar cáncer renal ${ }^{27}$. Los tumores se desarrollan por degeneración del epitelio que recubre la capa interna de los quistes, se crean focos de hiperplasia que progresan posteriormente a displasia y, más adelante, originan tumores papilares y sólidos. Las neoplasias son generalmente de pequeño tamaño (menores de $3 \mathrm{~cm}$ ) y frecuentemente bilaterales y multifocales. La tasa de metástasis es del $20 \%$.

No se ha relacionado la etiología de la insuficiencia renal con el riesgo de padecer cáncer renal, aunque el riesgo de desarrollarlo es mayor, en una serie de 831.804 pacientes, en la originada por enfermedades congénitas y nefropatías tóxicas ${ }^{27}$. Existe una relación inversa con la nefropatía diabética, que se mantiene para otros tumores del aparato urinario, como el cáncer vesical. Puede estar sesgada por la menor supervivencia de los pacientes diabéticos evolucionados que inician hemodiálisis.

Dado que los pacientes en insuficiencia renal terminal no pueden sobrevivir sin diálisis, no es posible discernir el efecto del tratamiento del relacionado con la propia enfermedad. Se ha sugerido 28 que las interacciones de la sangre con las membranas de la hemodiálisis podrían tener efecto carcinogénico, aunque este aspecto no ha sido demostrado posteriormente.
La inmunosupresión en el enfermo trasplantado supone un factor de riesgo para el desarrollo de malignidades. En los pacientes portadores de un injerto renal funcionante se ha informado de una incidencia de cáncer renal entre 9 y 25 veces superior a la de la población general ${ }^{29}$.

\section{Obesidad}

La obesidad, definida como un índice de masa corporal igual o superior a $30 \mathrm{~kg} / \mathrm{m}^{2}$, es un problema en constante incremento en la sociedad actual. Su incidencia ha aumentado un $20 \%$ en los países industrializados en las últimas décadas. La obesidad supone un riesgo aumentado de padecer varios tipos de cáncer entre 1,5 y 3,5 veces al de la población general, principalmente cáncer de mama en postmenopáusicas, cáncer de endometrio, colon, riñón y adenocarcinoma de esófago ${ }^{30}$. Se estima que podrían evitarse hasta 90.000 muertes por cáncer al año en Estados Unidos controlando el sobrepeso ${ }^{31}$.

Existe una relación entre cáncer renal y obesidad demostrada en estudios de cohortes. Este riesgo se asoció en los primeros estudios sólo en mujeres, pero posteriormente se demostró que afectaba a ambos sexos ${ }^{32}$. El riesgo de padecer cáncer de riñón se eleva un $24 \%$ en los varones y un $34 \%$ en mujeres por cada $5 \mathrm{Kg} / \mathrm{m}^{2}$ 33. En un estudio de cohortes sobre más de 160.000 pacientes, el riesgo aparece en mujeres a partir de un índice de masa corporal de 25 , y en varones a partir de $30 \mathrm{~kg} / \mathrm{m}^{2.34}$. El riesgo relativo de padecer cáncer renal siendo obeso es del 2,3 para las mujeres y del 1,8 para los varones.

La prevalencia en ascenso del sobrepeso en el mundo occidental puede explicar, en parte, el incremento de la incidencia de cáncer de riñón ${ }^{35}$. La proporción de cáncer renal que se estima relacionada con el sobrepeso oscila entre el 40\% de Estados Unidos y el 30\% de Europa.

Como mecanismos patogénicos se han propuesto cambios hormonales inducidos por la obesidad que producen elevados niveles de insulina y esteroides sexuales, el tejido adiposo es el mayor órgano endocrino en los mamíferos. La peroxidación lipídica y el estrés oxidativo que acompaña a la obesidad pueden causar daños en el DNA. Las adipokinas, (citokinas derivadas del tejido adiposo) como la adiponectina, pueden estar conectadas con mecanismos relacionados con la tumorigenesis. Este polipéptido tiene un demostrado efecto antiangiogénico ${ }^{36}$. Por razones no bien conocidas, sus valores plasmáticos están des- 
cendidos en los individuos con sobrepeso ${ }^{37}$. Los niveles de aponectina son claramente inferiores a partir de índices de masa corporal mayores de 30 $\mathrm{kg} / \mathrm{m}^{2}$. Este hecho se ha relacionado con carcinomas renales de mayor tamaño y enfermedad metastásica ${ }^{38}$.

\section{Hipertensión}

Los niveles de TAD superiores a $100 \mathrm{mmHg}$ y TAS superiores a $160 \mathrm{mmHg}$ suponen un riesgo dos veces superior al de la población general para padecer cáncer de riñón. Este riesgo es un factor independiente y se añade a otros factores como el tabaquismo y la obesidad, si coexisten.

Estudios en ratas han relacionado el uso de furosemida e hidroclorotiazida con el crecimiento de tumores renales ${ }^{39}$. Aunque se ha intentado vincular el uso de fármacos antihipertensivos con el desarrollo de la enfermedad, la propia hipertensión supone un factor de confusión y no se ha demostrado. El riesgo disminuye cuando se logran mantener las cifras tensionales bajo niveles normales y la influencia de los fármacos antihipertensivos estudiados, aunque parece relevante al inicio del seguimiento, resulta inexistente a los cinco años ${ }^{40,41}$. Por otro lado, un estudio reciente sobre 161.126 pacientes concluye que el uso de diuréticos incrementa el riesgo en mujeres, una vez corregida la confusión por la presencia de hipertensión ${ }^{34}$. Posibles explicaciones a este hecho incluyen una mayor exposición de las mujeres al uso de estos fármacos y la presencia de estrógenos, que en modelos animales aumenta el efecto de los diuréticos en los túbulos renales.

Aunque el mecanismo patogénico que subyace a esta relación hipertensión/cáncer renal es desconocido, se especula sobre el efecto de la hipoxia renal crónica que acompaña a la hipertensión y la peroxidación lipídica. Una explicación al posible efecto de los diuréticos es el efecto de éstos sobre las células de los túbulos renales, origen de la enfermedad neoplásica.

\section{Analgésicos}

El abuso crónico de analgésicos conteniendo fenacetina se ha relacionado claramente con el desarrollo de carcinoma de urotelio en tracto urinario superior. Sin embargo no se ha demostrado de forma concluyente un mayor riesgo para el adenocarcinoma renal. Este fármaco está en desuso desde hace más de dos décadas, por lo que no existen datos actuales que permitan aclarar su papel la como carcinógeno en el carcinoma renal.

El acetaminofen, un metabolito de la fenacetina, y la aspirina, han estado incluidos en la mayoría de los estudios para establecer una relación entre la toma de AINEs y cáncer renal, sin que se haya demostrado la misma ${ }^{41,43}$.

\section{Factores ocupacionales}

Varios estudios epidemiológicos han buscado relación entre el cáncer de riñón y exposición a determinados productos industriales. La exposición a asbestos muestra un riego relativo de 1,4 de padecer cáncer de riñón que, sin embargo, no se corrobora en todos los estudios epidemiológicos y probablemente la vinculación sea débil ${ }^{44}$.

Los derivados del petróleo, como la gasolina, inducen el desarrollo de tumores renales en ratas de laboratorio. Sin embargo, no se ha corroborado ninguna relación en estudios epidemiológicos entre la exposición a gasolina y el riesgo de padecer cáncer de riñón ${ }^{45-47}$.

El tricloroetileno es un potente disolvente de materiales orgánicos, utilizado ampliamente en la industria metalúrgica, alimentaria, e incluso, como anestésico hasta la sexta década del siglo pasado. Se relacionó la exposición a este producto con una mayor incidencia de cáncer de riñón. Esta relación se ha demostrado débil en un estudio realizado sobre más de 40.000 trabajadores expuestos ${ }^{48}$. Un estudio reciente casos control de trabajadores expuestos en Francia sugiere que no existe una relación con el desarrollo de cáncer de riñón ${ }^{49}$. Sin embargo, estos mismos autores habían comunicado un riesgo acumulativo con la exposición a esta sustancia que puede alcanzar un incremento de hasta el $64 \%{ }^{50}$. Los datos son, por tanto, contradictorios y son necesarias nuevas investigaciones.

Existe una asociación entre la exposición ocupacional a pesticidas y la enfermedad. Dicha relación afecta a individuos con polimorfismos específicos del gen de la glutatión S-transferasa (GST) ${ }^{51}$. Las enzimas de la GST intervienen en la conjugación de mediadores tóxicos, entre ellos los hidrocarburos policíclicos aromáticos. Los polimorfismos más frecuentemente estudiados en este grupo de genes, en relación con el riesgo de cáncer de riñón son el genotipo GSTM1 y el GSTT1. La presencia de cualquiera de los genotipos dobla el riesgo de padecer cáncer renal. Los mediadores conjugados pueden resultar tóxicos para el epite- 
lio tubular. Los trabajadores expuestos que expresan dichos genotipos pueden presentar mayor riesgo de cáncer de riñón.

El grupo de enzimas del citocromo P450 (CYP), de las que se han identificado 17 familias en humanos, intervienen en la transformación de posibles carcinógenos ambientales. La CYP1A1 y la CYP1B1 transforman los hidrocarburos policíclicos en epóxidos, con posible efecto carcinogénico ${ }^{52}$.

Otras ocupaciones en las que se produce exposición a diversos compuestos como cadmio, cromo, sulfato de cobre, plomo se han relacionado, sin que exista evidencia suficiente, con el riesgo de desarrollar cáncer renal ${ }^{18}$.

\section{Hábitos alimentarios}

La diferencia de incidencia del carcinoma renal entre los países occidentales y Asia sugiere que pueda existir una influencia dietética. La dieta asiática incluye más vegetales y menos grasas animales. Un estudio de casos control sobre 1.279 pacientes y un grupo control de 5.370 individuos determinó un menor riesgo de cáncer renal asociado con una elevada ingesta de vegetales. Igualmente fueron protectores la vitamina $\mathrm{E}$ y el calcio en mujeres y la vitamina $\mathrm{E}$ y los suplementos de hierro en varones ${ }^{53}$.

Varios estudios casos control han sugerido que existe una relación entre la ingesta de grasas y proteínas y el desarrollo de cáncer renal. Sin embargo, estos efectos no han sido claramente establecidos. Un análisis de 13 estudios prospectivos que enrolan en total cerca de 800.000 individuos evalúa el efecto de la ingesta de carne, grasas y proteínas en el riesgo de padecer cáncer renal. Dicho estudio refiere una asociación positiva estadísticamente significativa con la ingesta de grasas y proteínas. Sin embargo, esta relación pierde significación estadística al ajustar por índice de masa corporal, ingesta de vegetales y fruta e ingesta de alcohol. Concluye que no existe relación entre la ingesta de grasas y proteínas de cualquier tipo y el desarrollo de cáncer renal ${ }^{54}$.

La ingesta de alcohol se ha relacionado con un descenso del riesgo de hasta el $28 \%$ en aquellos que beben más de $15 \mathrm{~g} / \mathrm{d}^{55}$. Este supuesto efecto protector incluye a todo tipo de bebidas alcohólicas. Otras bebidas como té, café, leche, zumos o ingesta de agua no tienen efecto.

La presencia en el agua potable de trazas de arsénico, nitratos y diversos isótopos radioactivos, principalmente uranio 238 no se ha asociado con mayor riesgo de cáncer renal ${ }^{18}$.

\section{Riesgo genético y carcinoma renal hereditario}

Alrededor del $4 \%$ de los carcinomas renales están asociados con síndromes hereditarios. La presencia de lesiones renales múltiples sugestivas de neoplásicas o la historia familiar de cáncer renal, sobre todo si se trata de personas jóvenes, sugiere predisposición genética para padecer la enfermedad.

En la enfermedad esporádica, el riesgo de padecer cáncer de riñón se incrementa un $50 \%$ si el familiar afectado es el padre o la madre y hasta cuatro veces si es un hermano ${ }^{56}$. Esta vinculación se extiende a familiares de segundo y tercer grado.

Varios grupos de genes se han relacionado con el riesgo de padecer cáncer renal esporádico:

Los genes de la glutatión-S-transferasa, principalmente los polimorfismos GSTM1 y GSTT1.

La vinculación con polimorfismos del receptor de la vitamina D (VDR), como el TaqI y el ApaI, muestran datos contradictorios y son necesarios nuevos estudios que establezcan el papel de este receptor en la predisposición al cáncer renal ${ }^{57}$

Los genes CHECK2 y cyclin D1 (CCND1) intervienen en el control del ciclo celular y se ha relacionado con el cáncer renal.

Cuatro síndromes hereditarios suponen un riesgo de padecer carcinoma renal: enfermedad de Von Hippel Lindau, leiomiomatosis hereditaria y carcinoma renal, síndrome de Birt-Hogg-Dubé y carcinoma papilar hereditario. El estudio de estos síndromes hereditarios ha supuesto un gran avance en el conocimiento de las bases genéticas del carcinoma renal y, actualmente, se conocen los genes implicados en cada uno de ellos.

\section{Enfermedad de Von Hippel-Lindau}

En la enfermedad de Von Hippel Lindau, autosómica dominante, un alelo del gen supresor VHL, situado en el cromosoma 3p25-26 y descrito por primera vez en $1993^{58}$, se transmite mutado, el alelo restante se pierde por delección ${ }^{59}$. La enfermedad afecta a 1 de cada 36.000 habitantes en la población general. Tiene una penetrancia (expresión del fenotipo en portadores) del $80-90 \%$, pero las manifestaciones clínicas son variables incluso dentro de una misma familia; los enfermos con la variante tipo I no presentan feocromocitoma, la variante Ila presenta feocromocitoma y hemangioblastomas del SNC, y la Ilb asocia afectación pancreática. Los pacientes afectos desarrollan carcinoma renal de células cla- 
ras en alrededor del 50\% de los casos, característicamente de inicio temprano (a partir de la $3^{\mathrm{a}}-4^{\mathrm{a}}$ décadas de vida), multifocal y recidivante. Otras manifestaciones de esta enfermedad son: angiomas retinianos (49-59\%), hemangioblastomas benignos (42-72\%), quistes renales (22-59\%), feocromocitoma (18\%), tumores pancreáticos (12\%), quistes pancreáticos (21-72\%), cistadenoma de epidídimo (10$26 \%$ ) y tumor del saco endolinfático en el oído interno (10\%). Las lesiones de inicio en la enfermedad son los hemangioblastomas hereditarios, a una edad media de 25 años.

El producto del gen VHL es la proteína del mismo nombre, que actúa como un supresor tumoral. La proteína VHL se ha relacionado con la inhibición de genes implicados en la angiogénesis, estimulados en situaciones de hipoxia celular. El desarrollo de las lesiones tumorales, en los distintos tejidos afectados por la enfermedad, surge por la falta de expresión o inactivación del alelo normal (generalmente por delección), esto lleva a la producción de la proteína VHL defectuosa codificada por el alelo mutado, y permite la sobreexpresión de proteínas implicadas en la angiogénesis, como VEGF, TGF-alfa, GLUT-1, creando un ambiente que favorece la proliferación de las células epiteliales ${ }^{60}$. La proteína VHL se liga a la proteína cul2, actuando como promotor de para la ubiquitinización y destrucción de proteínas ${ }^{60}$. La acción de la proteína VHL se ha implicado en la degradación mediante hidroxilación del HIF-1alfa y HIF-2alfa, factores activadores hipoxia-inducible, implicados en la estimulación de la trascripción de factores como el VEGF, en situaciones de estrés como la hipoxia. Esta es una vía de carcinogénesis de vital importancia, ya que el HIF-alfa es un factor central en la respuesta a la hipoxia de los organismos multicelulares ${ }^{61,62}$, y es un blanco potencial de fármacos-diana que actúen directamente sobre la misma. El crecimiento de células neoplásicas de carcinoma renal se detiene al provocar in vitro la inactivación del HIF-alfa. Sin embargo, su sobreexpresión no es suficiente para iniciar la tumorigénesis ${ }^{63}$.

La mutación del gen VHL está también implicada en hasta el 91\% de los casos de carcinoma renal esporádico, no hereditario. Un dato reciente que supera el 60\% de estudios previos y que puede deberse a que estaban basados en muestras archivadas de tejidos ${ }^{64}$. La delección ocurre virtualmente en todos los carcinomas renales esporádicos.

\section{Carcinoma renal papilar familiar}

El carcinoma renal papilar familiar presenta herencia autosómica dominante. Las lesiones son multifocales, bilaterales y pertenecen al tipo celu$\operatorname{lar} 1^{65}$. La edad media de presentación es a los 45 años, la proporción varón:mujer es de 2:1. La penetrancia de la enfermedad es del 50\%. La causa genética de esta enfermedad se sitúa en el cromosoma 7q31-34, que está duplicado. En este cromosoma se encuentra el gen MET. Se trata de un proto-oncogen que codifica un receptor tirosin-kinasa de la membrana celular. El receptor, al que se liga el factor de crecimiento hepatocitario, se encuentra sobreexpresado y mutado, se autoactiva, promoviendo la carcinogénesis, ya que interviene en la proliferación del tejido epitelial y endotelial ${ }^{66}$. Sólo un pequeño porcentaje de los carcinomas renales papilares esporádicos muestran la mutación del gen MET.

\section{Sindrome de leiomatosis hereditaria y carcinoma renal familiar}

En este síndrome, al desarrollo de múltiples leiomiomas cutáneos y uterinos se asocia el riesgo de padecer carcinoma renal papilar. La lesión es característicamente única y pertenece al tipo histológico $2^{67}$. Puede en ocasiones asociar carcinoma renal de células claras y carcinoma de conductos colectores. La herencia es autosómica dominante y reside en el gen $\mathrm{FH}$, situado en el cromosoma 1q42-44, uno de cuyos alelos está deleccionado en los enfermos de este síndrome. Este gen se comporta como un supresor tumoral y sintetiza una enzima del ciclo de Krebs, la fumarato hidratasa ${ }^{68}$.

El 20\% de los enfermos de leiomatosis hereditaria se diagnosticarán de carcinoma renal, que demuestra una gran agresividad local y tendencia a desarrollar metástasis precoces.

\section{Oncocitoma y carcinoma renal cromófobo}

El síndrome de Birt-Hogg-Dubé es otra enfermedad de herencia autosómica dominante, descrita en 1977, que asocia en un 20\% de los casos focos múltiples de neoplasias renales. Histológicamente corresponden a carcinomas renales cromófobos y oncocitomas, o tumores que muestran características histológicas mixtas. En ocasiones desarrollan carcinomas con histología papilar o de células claras ${ }^{69}$.

Clínicamente, los pacientes afectados por este síndrome presentan, además, hamartomas de los folículos pilosos de cara y cuello (fibrofoliculomas), 
quistes pulmonares y neumotórax espontáneo. El sustrato genético del sindrome está causado por la mutación del gen BHD1, en el cromosoma 17 p11.2, que codifica la proteína $\mathrm{BDH}$, también llamada foliculina. Se comporta como un supresor tumoral ${ }^{70}$. En los pacientes afectados por este sindrome, los tumores renales parecen manifestar un comportamiento especialmente poco agresivo, y, a pesar de la multifocalidad de las lesiones, pocos enfermos desarrollan metástasis.

\section{REFERENCIAS}

1. Ferlay J, Autier P, Boniol M, Heanue M, Colombet M, Boyle P. Estimates of the cancer incidence and mortality in Europe in 2006. Annals of Oncology. 2007;18(3):581-592.

2. Jemal A, Siegel R, Ward E, Murray T, Xu J, Smigal C, et al. Cancer statitics, 2006. A cancer Journal for Clinicians. 2006; 56(2): 106-130

3. Stafford HS, Saltzstein SL, Shimasaki S, Sanders C, Downs TM, Robin s Sadler G. Racial/ethnic and gender disparities in renal cell carcinoma incidence and survival. J Urol 2008;179(5): 1704-1708.

4. Aron M, Nguyen MM, Stein RJ, Gill IS. Impact of gender in renal cell carcinoma: an analysis of the SEER database. Eur Urol. 2008;54(1):133-140.

5. Chow WH, Devesa SS, Warren JL, Fraumeni JF Jr. Rising incidence of renal cell cancer in the United States. JAMA. 1999;281(17):1628-1631.

6. Pascual D, Borque A. Epidemiology of kidney cancer. Adv Urol; 2008: art ID 782381.

7. Mathew A, Devesa SS, Fraumeni JF, Chow WH. Global increases in kidney cancer incidence, 1973-1992. Eur J Cancer Prev. 2002;11(2):171-178.

8. Hock LM, Lynch J, Balaji KC. Incidence of all stages of kidney cancer in the last 2 decades in the United States: an analysis for Surveillance, Epidemiology and End Results program data. J Urol. 2002;167(1):57-60.

9. Kane CJ, Mallin K, Ritchey J, Coopenberg MR, Carroll P. Renal Cell Cancer Stage Migration: analysis of the National Cancer Data Base. Cancer. 2008;113(1):78-83.

10. Woldrich JM, Mallin K, Ritchey J, Carroll PR, Kane CJ. Sex differences in renal cell cancer presentation and survival: an analysis of the National Cancer Database, 1993-2004. J Urol 2008;179(5): 1709-1713.

11. Levi F, Ferlay J, Galeone C, Lucchino F, Negri E, Boyle P, et al. The changing pattern of kideny cancer incidence and mortality in Europe. BJU Int. 2008;101(8):949-958.

12. Lopez-Abente G, Pollan M, Aragones N, Perez-Gomez B, Llácer A, Pérez J, et al.: Tendencias de la mortalidad en España, 1952-1996. Efecto de la edad, de la cohorte de nacimiento y del periodo de muerte Madrid. Instituto de Salud Carlos III;.2002.

13. Gonzalo López-Abente, Rebeca Ramis, Marina Pollán, Nuria Aragonés, Beatriz Pérez-Gómez, Diana Gómez-Barroso, José Miguel Carrasco, Virginia Lope-Carvajal, Javier García-Pérez, Elena Boldo, María José García-Mendizábal. Atlas Municipal de mortalidad por cácner en España, 1989-1998. 2007. Instituto de Salud CarlosIII.www.iscii.es/htdocs/centros/epi-demiologia/libros.

14. Gonzalo López-Abente, Nuria Aragonés, Beatriz Pérez-Gómez, Rebeca Ramis, Enrique Vidal, Javier García-Pérez, Pablo Fernández-Navarro and Marina Pollán. Kidney cancer mortality in Spain: geographic patterns and possible hypotheses. BMC Cancer 2008;8:293.
15. Garcia-Perez J, Boldo E, Ramis R, Pollan M, Perez-Gomez B, AragonesN, Lopez-Abente G: Description of industrial pollution in Spain. BMC Public Health 2007, 7:40.

16. Setiawan VW, Stram DO, Nomura AM et al. Risk factors for renal cell cancer: the multiethnic cohort. Am J Epidemiol 2007; 166: 932-940.

17. Loren Lipworth, Robert E Tarone, J K McLaughin. The epidemiology of renal cell carcinoma. The Journal of Urology. 2006; 176(6):2353-2358.

18. Wong-Ho Chow, Susan S. Devesa. Contemporary Epidemiology of Renal Cell Cancer. The Cancer Journal. 2008 14: 288-301.

19. Jay D. Hunt, Olga L. van der Hel, Garnett P. McMillan, Paolo Boffetta and Paul Brennan. Renal cell carcinoma in relation to cigarette smoking: Meta-analysis of 24 studies. Int. J. Cancer 2005 114:101-108.

20. Sharifi N, Farrar WL. Perturbations in hypoxia detection: a shared link between hereditary and sporadic tumor formation?. Med Hypotheses. 2006;66(4):732-735.

21. Zhu Y, Horikawa Y, Yang H, Wood CG, Habuchi T, Wu X. BPDE Induced Lymphocytic Chromosome 3p Deletions May Predict Renal Cell Carcinoma Risk. J Urol. 2008;179(6):2416-2421.

22. Bjerregaard BK, Raaschou-Nielsen O, Sørensen M, Frederiksen K, Tjønneland A, Rohrmann S, et al. The effect of occasional smoking on smoking-related cancers: in the European Prospective Investigation into Cancer and Nutrition (EPIC). Cancer Causes Control. 2006;17(10):1305-1309.

23. Hu J, Ugnat AM, Canadian Cancer Registries Epidemiology Research Group. Active and passive smoking and risk of renal cell carcinoma in Canada. Eur J Cancer. 2005;41(5):770-778.

24. Parker AS, Cerhan JR, Janney CA, Lynch CF, Cantor KP. Smoking cessation and renal cell carcinoma. Ann Epidemiol. 2003; 13(4):245-251.

25. Bretan PN, Busch MP, Hricak H, Williams RD. Chronic renal failure. A significant risk factor in the development of acquired renal cysts and renal cell carcinoma. Cancer. 1986;57(9):18711879.

26. Ishikawa I. Uremic acquired renal cystic disease. Natural History and complications. Nephron. 1991;58(3):257-267.

27. Stewart JH, Buccianti G, Agodoa L, Gellert R, McCredie MR, Lowenfels AB, et al. Cancers of the Kidney and Urinary tract in patients on dialysis for end-stage renal disease: analysis of data from the United States, Europe and Australia and New Zealand. J Am Soc Nephrol. 2003;14(1):197-207.

28. Akizawa T, Kinugasa E, Koshikawa S. Increased risk of malignancy and blood-membrane interactions in uraemic patients. Nephrol Dial Transplant. 1994;9 Suppl 2:162-164.

29. Gaya SB, Rees AJ, Lechler RI, Williams G, Mason PD. Malignant disease in patients with long term transplants. Transplantation. 1995;59(12):1705-1709.

30. Pischon T, Nöthlings U, Boeing H. Obesity and cancer. Proc Nutr Soc. 2008;67(2):128-145.

31. Calle EE, Rodriguez C, Walker-Thurmond K, Thun MJ. Overweight, Obesity, and Mortality from Cancer in a Prospectively Studied Cohort of U.S. Adults. N Engl J Med. 2003;348(17):1625-1638.

32. Wolk A, Gridley G, Niwa S, Lindblad P, McCredie M, Mellemgaard A, et al. International renal-cell cancer study, VII. Role of diet. Int J Cancer. 1996;65(1):67-73.

33. Renehan AG, Tyson M, Egger M, Heller RF, Zwahlen M. Bodymass index and incidenceof cancer: a systematic review and meta-analysis of prospective observational studies. Lancet. 2008;371(9612):569-578.

34. Setiawan VW, Stram DO, Nomura AM, Kolonel LN, Henderson BE. Risk factors for renal cell cancer: the multiethnic cohort. Am J Epidemiol. 2007;166(8):932-940. 
35. Lipworth L, Tarone RE, McLaughlin JK. The epidemiology of renal cell carcinoma. The Journal of Urology. 2006;176(6 Pt 1): 2353-2358.

36. Bråkenhielm E, Veitonmäki N, Cao R, Kihara S, Matsuzawa Y, Zhivotovsky B, et al. Adiponectin-induced antiangiogenesis and antitumor activity involve caspase-mediated endothelial cell apoptosis. Proc Natl Acad Sci U S A. 2004;101(8):2476-2481.

37. Arita Y, Kihara S, Ouchi N, Takahashi M, Maeda K, Miyagawa $J$, et al. Paradoxical decrease of an adipose-specific protein, adiponectin, in obesity. Biochem Biophys Res Commun. 1999; 257(1):79-83.

38. Zigeuner R. Lower Plasma Adiponectin Levels Are Associated with Larger Tumor Size and Metastasis in Clear-Cell Carcinoma of the Kidney. Eur Urol. 2008;54 (4): 873-874.

39. McLaughlin JK, Lipworth L. Epidemiologic aspects of renal cell cancer. Semin Oncol.2000;27(2):115-123.

40. Fryzek JP, Poulsen AH, Johnsen SP, McLaughlin JK, Sørensen HT, Friis S. A cohort study of antihypertensive treatments and risk of renal cell cancer. Br J Cancer. 2005;92(7):1302-1306.

41. Chow WH, Gridley G, Fraumeni JF Jr, Järvholm B. Obesity, hypertension, andthe risk of kidney cancer in men. N Engl J Med. 2000;343(18):1305-1311.

42. McCredie M, Pommer JK, McLaughin JH, Stewart JH, Lindblad P, Mandel JS, et al. International renal cell cancer study II. Analgesics. Int J Cancer. 1995;60(3):345-349.

43. Rosemberg L, Rao RS, Palmer JR, Strom BL, Zauber A, Warshauer ME, et al. Transitional cell cancer of the urinary tract and renal cell cancer in relation to acetaminophen use (United States). Cancer Causes Control. 1998;9(1):83-88.

44. Sali D, Boffetta P. Kidney cancer and occupational exposure to asbestos: a meta-analisis of occupational cohort studies Cancer Causes Control. 2000;11(1):37-47.

45. Lohi J, Kyyrönen P, Kauppinen T, Kujala V, Pukkala E. Occupational exposure to solvents and gasoline and risk of cancers in the urinary tract among Finnish workers. Am J Ind Med. 2008;51(9):668-672.

46. Wong O, Trent L, Harris F. Nested case control study of leukemia, multiple myeloma and kidney cancer in a cohort of petroleum workers exposed to gasoline. Occup Environ Med 1999;56(4):217-221.

47. Lewis RJ, Schnatter AR, Drummond N, Murray FS, Thompson FS, Katz AM, et al. Mortality and cancer morbidity in a cohort of canadian petroleum workers. Occup Environ Med. 2003;60(12):918-928.

48. Raaschou-Nielsen O, Hansen J, McLaughlin JK, Kolstad H, Christensen JM, Tarone RE, et al. Cancer risk among workers at Danish companies using trichloroethylene: a cohort study. Am J Epidemiol. 2003;158(12):1182.

49. Charbotel B, Fevotte J, Martin JL, Bergeret A. Renal cell carcinoma and exposure to trichloroethylene: Are French occupational exposure limits relevant?. Rev Epidemiol Sante Publique. 2009;57(1):41-47.

50. Charbotel B, Fevotte J, Hours M, Martin JL, Bergeret A. Casecontrol study on renal cell cancer and occupacional exposure to trichloroethylene. Part II: epidemiological aspects. Ann Occup Hyg. 2006;50(8):777-787.

51. Karami S, Boffetta P, Rothman N, Hung RJ, Stewart T, Zaridze D, Navritalova M, Mates D, Janout V, Kollarova H, Bencko V, Szeszenia-Dabrowska N, Holcatova I, Mukeria A, et al. Renal cell carcinoma, occupational pesticide exposure and modification by glutathione S-transferase polymorphisms. Carcinogenesis. 2008;29(8):1567-1571.

52. Murai M, Oya M. Renal cell carcinoma: etiology, incidence and epidemiology. Curr Opin Urol. 2004;14(4):229-233.

53. Hu J, Mao Y, White K; Canadian Cancer Registries Epidemiology Research Group.. Diet and vitamin or mineral supplements and risk of renal carcinoma in Canada. Cancer Causes Control. 2003:14(8):705-714.
54. Lee JE, Spiegelman D, Hunter DJ, Albanes D, Bernstein L, van den Brandt PA, et al. Fat, protein, and meat consumption and renal cell cancer risk: a pooled analysis of 13 prospective studies. J Natl Cancer Inst. 2008;100(23):1658-1659.

55. Lee JE, Hunter DJ, Spiegelman D, Adami HO, Albanes D, Bernstein L, et al. Alcohol intake and renal cell cancer in a pooled analysis of 12 prospective studies. J Natl Cancer Inst. 2007; 99(10):801-810.

56. Dong C, Hemminski K. Modification of cancer risks in offsprings by siblings and parental cancers from 2112616 nuclear families. Int J Cancer. 2001;92(1):144-150.

57. Karami S, Brennan P, Hung RJ, Boffetta P, Toro J, Wilson RT, et al. Vitamin D receptor polymorphirms and renal cancer risk in Central and Eastern Europe. J Toxicol Environ Health. 2008;71(6):367-372.

58. Latif F, Tory K, Gnarra J, Yao M, Duh FM, Orcutt ML, et al. Identification of the von Hippel-Lindau disease tumor suppressor gene. Science. 1993;260(5112):1317-1320.

59. Stolle C, Glenn G, Zbar B, Humphrey JS, Choyke P, Walther M, et al. Improved detection of germline mutations in the von Hippel-Lindau disease tumor suppresor gene. Human Mutation. 1998;12(6):417-423.

60. Cohen HT, McGovern FJ. Renal-Cell Carcinoma. N Engl J Med. 2005;353(23):2477-2490.

61. Maxwell PH, Wiesener MS, Chang GW, Clifford SC, Vaux EC, Cockman ME, et al. The tumour suppressor protein VHL targets hypoxia-inducible factors for oxygen-dependent proteolysis. Nature.1999;399(6733):271-275.

62. Cockman ME, Masson N, Mole DR, Jaakkola P, Chang GW, Clifford SC, et al. Hypoxia inducible factor-alpha binding and ubiquitylation by the von Hippel-Lindau tumor suppressor protein. J Biol Chem. 2000;275(33):25733-25741.

63. Kondo K, Kim WY, Lechpammer M, Kaelin WG Jr. Inhibition of HIF2alpha is sufficient to suppress pVHL-defective tumorgrowth. PLoS Biol 2003;1(3):E83.

64. Nickerson ML, Jaeger E, Shi Y, Durocher JA, Mahurkar S, Zaridze D, et al. Improved identification of Von Hippel-Lindau gene alterations in clear cell renal tumors. Clin Cancer Res. 2008; 14(15):4726-4734.

65. Zbar B, Glenn G, Lubensky I, Choyke P, Walther MM, Magnusson G, et al. Hereditary papillary renal cell carcinoma: clinical studies in 10 families. J Urol. 1995;153(3 Pt 2):907-912.

66. Fischer J, Palmedo G, von Knobloch R, Bugert P, Prayer-Galetti $\mathrm{T}$, Pagano F, et al. Duplication and overexpression of themutant allele of the MET proto-oncogene in multiple hereditary papillary renal cell tumours. Oncogene. 1998;17(6):733-739.

67. Launonen V, Vierimaa O, Kiuru M, Isola J, Roth S, Pukkala E, et al. Inherited susceptibility to uterine leiomyomas and renal cell cancer. Proc Natl Acad Sci USA. 2001;98(6):3387-3392.

68. Tomlinson IP, Alam NA, Rowan AJ, Barclay E, Jaeger EE, Kelsell D, et al. Germline mutations in $\mathrm{FH}$ predispose to dominantly inherited uterine fibroids, skin leiomyomata and papillary renal cell cancer. Nat Genet. 2002;30(4):406-410.

69. Pavlovich CP, Walther MM, Eyler RA, Hewitt SM, Zbar C, Linehan WM, et al. Renal tumors in the Birt-Hogg-Dubé syndrome. Am J Surg Pathol. 2002;26(12):1542-1552.

70. Nickerson ML, Warren MB, Toro JR, Matrosova V, Glenn G, Turner ML, et al. Mutations in a novel gene lead to kidney tumors, lung wall defects, and benign tumors of the hair follicle in patients with the Birt-Hogg-Dube syndrome. Cancer Cell. 2002;2(2):157-164

Correspondencia autor: Dr. Francisco J. Anglada Curado Servicio de Urología. Hospital Regional Universitario Reina Sofía Avda. Menéndez Pidal, s/n - 14005 Córdoba. Tel.: 957010001 E-mail autor: ancusr@ono.com Información artículo: Original Trabajo recibido: marzo 2009 Trabajo aceptado: abril 2009 